International Journal of Instrumentation and Control Systems (IJICS) Vol.7, No.3, July 2017

\title{
REAL TIME DATA ACQUISATION OF SOLAR PANEL USING ARDUINO AND FURTHER RECORDING VOLTAGE OF THE SOLAR PANEL
}

\author{
Shubhankar Mandal ${ }^{1}$ and Dilbag Singh ${ }^{2}$ \\ ${ }^{1}$ M.Tech. Scholar and ${ }^{2}$ Associate Professor \\ Department of Control \& Instrumentation, \\ National Institute of Technology, Jalandhar, India
}

\begin{abstract}
This paper presents the simulation of real time data acquisition of a solar panelin LabVIEW. A prototype model has been made where two Arduino were used. One is used for interfacing the solar panel with the $P C$ for acquisition of data and the other one isused with the servomotor. The servomotor is linked with the solar panel with the help of a shaft and is rotated according to the LDR output. Two LDR is fixed on both the sides of the solar panel for tracing the sunlight. The whole simulation is performed with the help of LINX firmware wizard, which is available in LabVIEW Maker's Hub. Data were collected of different days in different duration of time. According to the collected data, behaviour and the voltage of the solar module was analysed. This paper describes the design of a low cost, solar tracking and real time data acquisition system.
\end{abstract}

\section{KEYWORDS}

Arduino (microcontroller), Servomotor, LabVIEW Makers Hub, LINX firmware wizard.

\section{INTRODUCTION}

As the energy demand and the environmental problems increase, the natural energy sources have become very important as an alternative to the conventional energy sources. The renewable energy sector is fast gaining ground as a new growth area for numerous countries with the vast potential [1]. Solar energy plays an important role as a primary source of energy, especially for rural area. This paper aims at the development of process to track the sun and attain maximum voltage using Arduino uno and LabVIEW for real time monitoring. This work is divided into two stages, which are hardware and software development. In hardware development, two light dependent resistor (LDR) has been used for capturing maximum light source. One servomotor is used to rotate the solar panel at maximum light source location sensing by LDR. The GUI (Graphical User Interface) is constructed by using LabVIEW. The performance of the system has been tested and analysed with static solar panel. Recently a real time environment has been created with the use of National Instrument compact RIO consisting of cRIO chasis and DAQ modules powered by LabVIEW. Panel voltage and current were acquired through various compact Data Acquisition (DAQ) modules [13]. Another effort has been made to design and develop a smart real time embedded Arduino based data logger for indoor and outdoor

DOI : 10.5121/ijics.2017.7303 
International Journal of Instrumentation and Control Systems (IJICS) Vol.7, No.3, July 2017

environment [18]. This paper mainly deals with the real time data acquisition and tracking the sunlight followed by recording of the voltages of the solar panel with the help of Arduino in LabVIEW Makers Hub.

\section{Photovoltaic EfFect}

A solar photovoltaic or solar cell is a device that changes light into electric current by means of the photoelectric effect. SPVs are used in several applications such as in railway signals, streetlight, and household appliances and to drive telecommunication systems which are located far away [5].

It has a p-type of silicon layer, which is placed on an n-type silicon layer, and the diffusion of electrons arises from the n-type material to the p-type material. In the p-type material, there are holes for accommodating the electrons. The n-type material is rich in electrons, so by the influence of the solar energy, the electrons move from the $\mathrm{n}$ - type material to $\mathrm{p}$ - type material and in the $\mathrm{p}-\mathrm{n}$ junction, they combine with holes. This generates a charge on both side of the $\mathrm{p}-\mathrm{n}$ junction to create an electric field. Because of this, a diode-like arrangement develops which promotes charge flow. This drift current equilibriums the diffusion of electrons and holes. The zone in which drift presently occurs is the depletion zone or space charge region that deficiencies the mobile charge carriers.

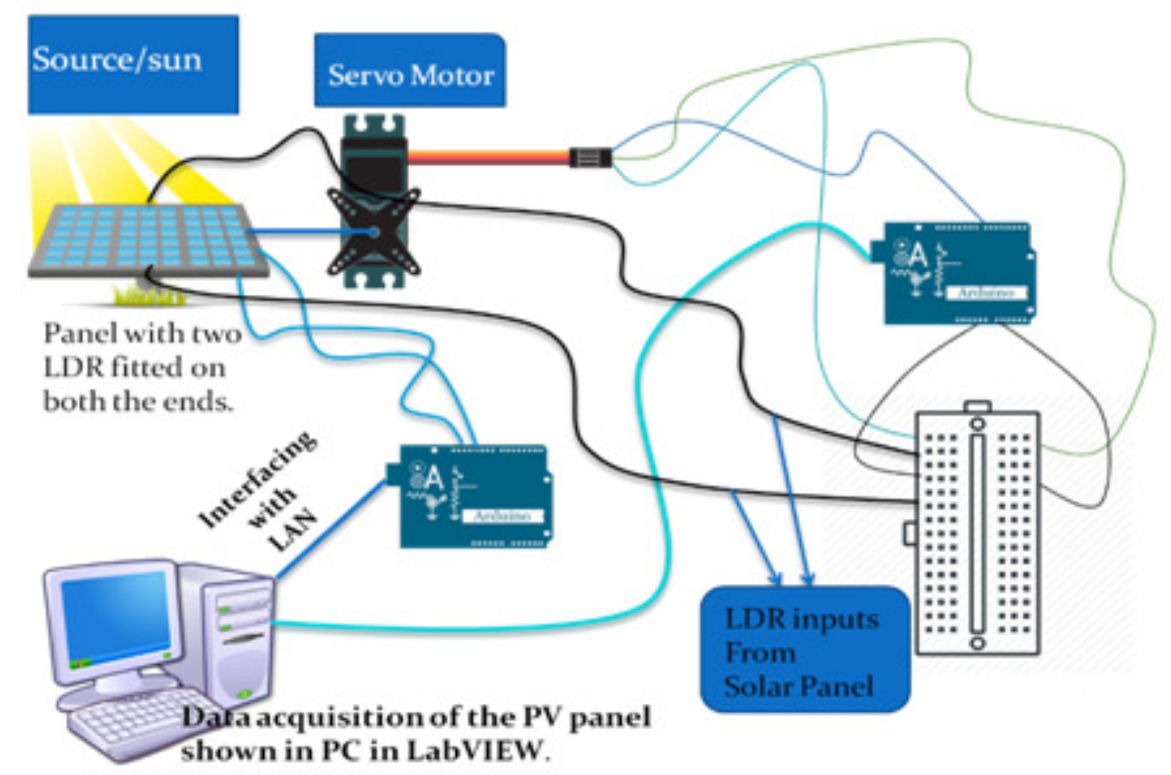

Figure 1. Schematic view of the system

For example, a 12-volt panel gives around 20 volts in bright sunlight. However, when the battery is connected to it, the voltage drops to $14-15$ volts. Solar photovoltaic (SPV) cells are made of extraordinary materials called semiconductors, for example, silicon, which is presently the most generally used. When light falls on the cell, a certain amount of it is absorbed within the semiconductor material. This means that the energy of the absorbed light is transported to the semiconductor [3] 


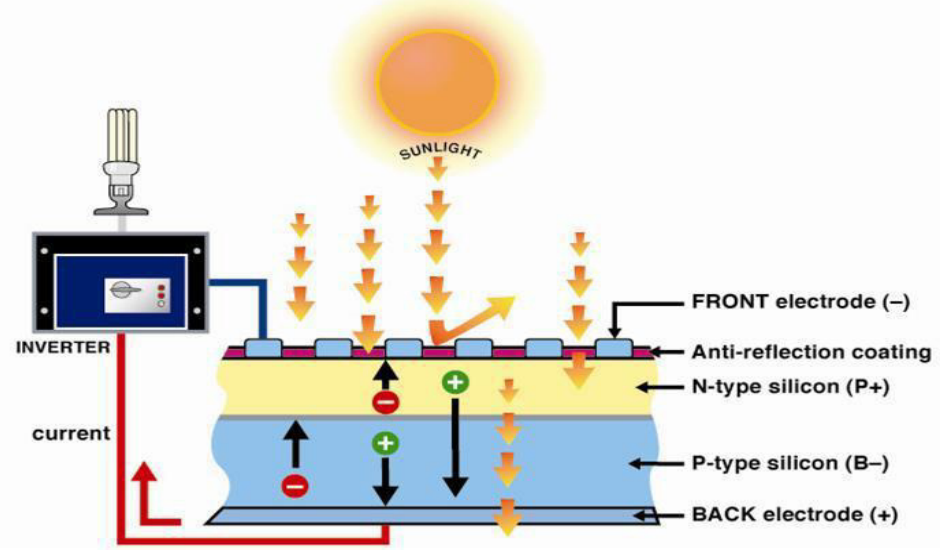

Figure 2. Solar photovoltaic cell [4]

\section{MICROCONTROLLER (ARDUINO)}

The Arduino Uno is a microcontroller board based on the ATmega328. It has 14 digital input/output pins, 6 analog inputs, a $16 \mathrm{MHz}$ crystal oscillator, a USB connection, a power jack, an ICSP header, and a reset button. It contains everything needed to support the microcontroller; simply connect it to a computer with a USB cable or power it with an AC-to-DC adapter or battery to get started. The Uno differs from all preceding boards in that it does not use the FTDI USB-to-serial driver chip. Instead, it features the Atmega8U2 programmed as a USB-to-serial converter.

"Uno" means one in Italian and is named to mark the upcoming release of Arduino 1.0. The Uno and version 1.0 will be the reference versions of Arduino, moving forward. The Uno is the latest in a series of USB Arduino boards, and the reference model for the Arduino platform; for a comparison with previous version [10].

\subsection{Technical Specification}

Microcontroller

Operating Voltage

Input Voltage (recommended)

Input Voltage (limits)

Digital I/O Pins

Analog Input Pins

DC Current per I/O Pin

DC Current for 3.3V Pin

Flash Memory

RAM

EEPROM

Clock Speed
ATmega328

$5 \mathrm{~V}$

$7-12 \mathrm{~V}$

$6-20 \mathrm{~V}$

14 (of which 6 provide PWM output)

6

$40 \mathrm{~mA}$

$50 \mathrm{~mA}$

$32 \mathrm{~KB}$ of which $0.5 \mathrm{~KB}$ used by bootloader

$2 \mathrm{~KB}$

$1 \mathrm{~KB}$

$16 \mathrm{MHz}$ 
International Journal of Instrumentation and Control Systems (IJICS) Vol.7, No.3, July 2017

\section{HARDWARE}

\subsection{Arduino-(UNO):}

The Arduino Uno is a microcontroller board centered on the ATmega328. It has 14 digital input/output pins ( out of which 6 can be used as PWM outputs), 6 analog inputs, an ICSP header, an USB connector, a power jack, a $16 \mathrm{MHz}$ crystal oscillator and a reset button. It contains every essential needs to support the microcontroller, simply it should be connected to a computer with an USB cable or it can be powered with an AC-to-DC adapter or battery to drive the Arduino[10].

\subsection{Servo Motor:}

It is a simple electrical motor, controlled with the help of servomechanism. If the motor controlled device is linked with servomechanism of DC motor, then it is usually known as DC Servo Motor. If AC operates the motor, it is called AC Servo Motor.

\subsection{LDR:}

A Light Dependent Resistor (LDR) or a photo resistor is a device whose resistivity is a function of the incident electromagnetic radiation. Hence, they are light sensitive devices. They are also called as photoconductive cells, photo conductors or simply photocells.

They are made up of semiconductor materials having high resistance.

\subsection{Solar panel:}

A solar photovoltaic or solar cell is a device that changes light into electric current by means of the photoelectric effect. SPVs are used in several applications such as in railway signals, streetlight, and household appliances and to drive telecommunication systems which are located far away.

\subsection{Connecting wire:}

Jumper wire has been used for connections. These are normally used interconnect the components of a breadboard or other prototype internally or with other equipment or components, without soldering.

\subsection{Breadboard:}

Breadboard is used to make temporary prototypes and to check circuit design. There is no need of soldering.

\subsection{Resistor:}

Two resistors of $10 \mathrm{ohm}$ have been used in this prototype model. 
International Journal of Instrumentation and Control Systems (IJICS) Vol.7, No.3, July 2017

\section{SOFTWARE}

Here LINX firmware wizard in LabVIEW has been used for interfacing with the Arduino.

LabVIEW file click on tools Gato Makers Hub Clicken LINX Firmware

\section{Wizard}

LINX provides easy to use LabVIEW VI's for interacting with common embedded platforms like Arduino, chip KIT and myRIO. Use the built in sensor VIs to start getting data to your PC in seconds or use the peripheral VIs to access your devices digital I/O, analog I/O, SPI, I2C, UART, PWM and more [11].
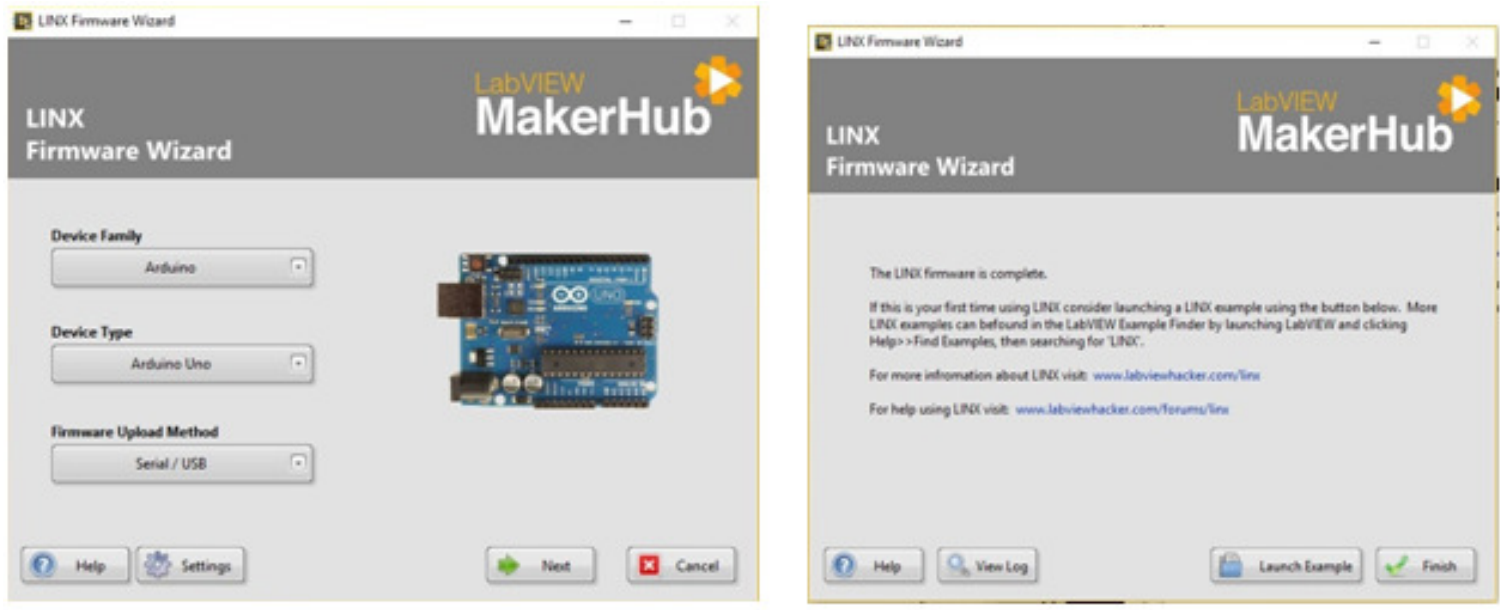

Figure 3. Pop up window of LINX firmware wizard

\subsection{IDE Software}

1 I Get an Arduino board and USB cable

2 I Download the Arduino Software (IDE)

3 I Connect the board

4 I Install the drivers

5 | Launch the Arduino application

6 I Open the blink example

7 I Select your board

8 I Select your serial port

9| Upload the program [12].

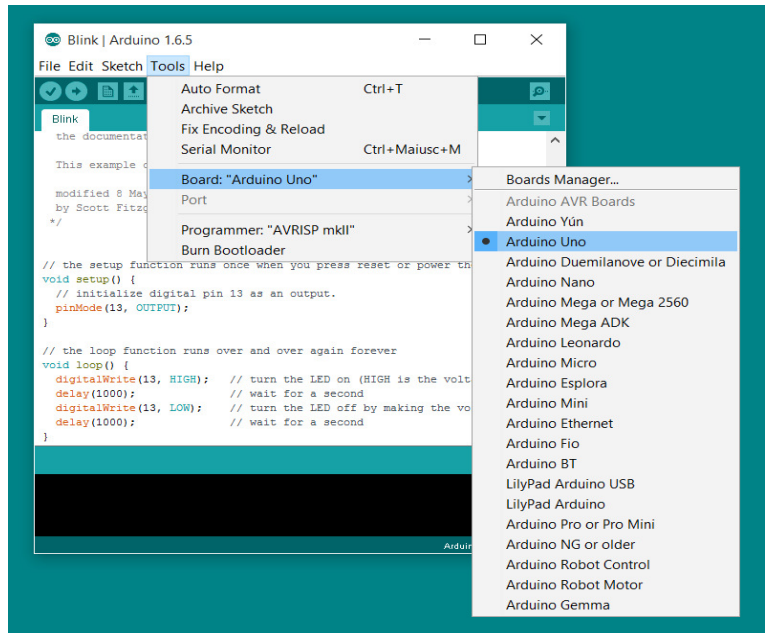

Figure 4. IDE Software window 
International Journal of Instrumentation and Control Systems (IJICS) Vol.7, No.3, July 2017

\section{METHODOLOGY}

Steps need to be followed as follows:

Step 1: Fix the servo motor with the help of a clamp.

Step 2: Now fix a small shaft with the solar panel so that it can be linked with the servomotor.

Step 4: Now fix a U shaped holder on the board so that the servomotor can be installed on it.

Step 5: Attach the LDRs on the two sides of the solar panel with the help of glue. Make sure the wires are soldered with the legs of the LDR's. You will have to connect these with the resistors later on.

Step 6: Now place the Arduino and the breadboard on the cardboard and make the connection as described in the Circuit diagram.

Step7: Next, connect the servo to the Arduino. Connect the positive wire of the servo to the 5V of Arduino and ground wire to the ground of the Arduino and then connect the signal wire of Servo to the digital pin 9 of Arduino. The servo will help in moving the solar panel.

Step 8: Now connect the LDRs to the Arduino. Connect one end of the LDR to the one end of the $10 \mathrm{k}$ resistor and also connect this end to the A0 of the Arduino and connect the other end of that resistor to the ground and connect the other end of LDR to the 5V. Similarly, connect the one end of second LDR to the one end of other 10k resistor, also connect that end to the A1 of Arduino, connect the other end of that resistor to ground, and connect the other end of LDR to $5 \mathrm{~V}$ of Arduino.

Step 9: Now to interface the solar panel with the PC another Arduino has been used. This Arduino is used only to acquire data from the panel. This real time data acquisition is simulated in LabVIEW software. The two wire coming out from the panel is connected to the input pins (A0, A1) of the Arduino.

Step 10: Upload the servo motor code with the help of IDE software.

Step 11: In the Front Pannel choose the correct 'Serial Port' and then run.

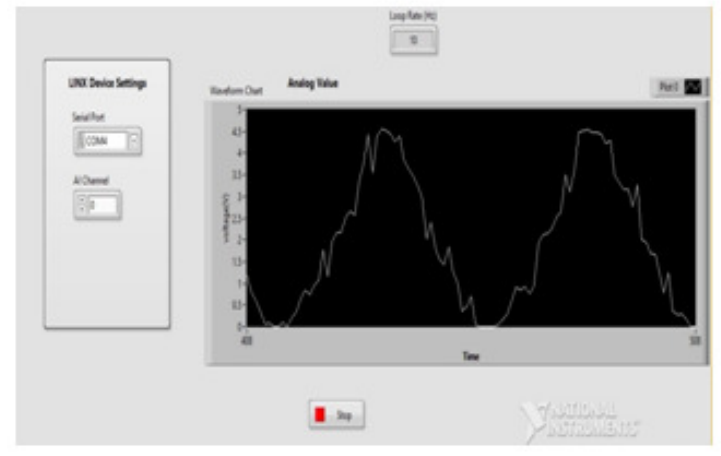

Figure 6. Front panel of the algorithm in LabVIEW

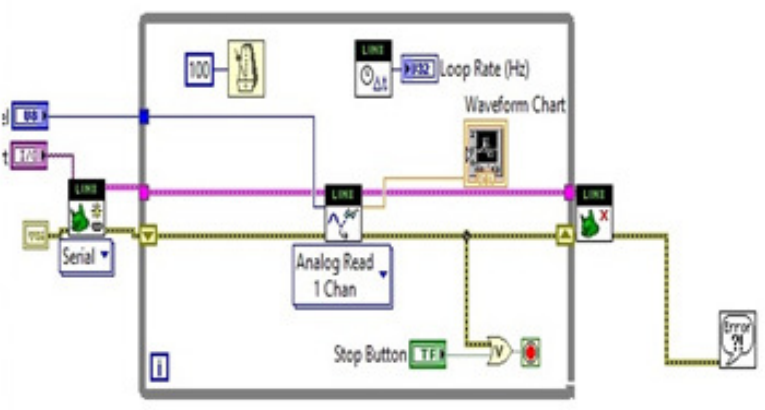

Figure 5. Block diagram of the algorithm 
International Journal of Instrumentation and Control Systems (IJICS) Vol.7, No.3, July 2017

\subsection{Final Project View}
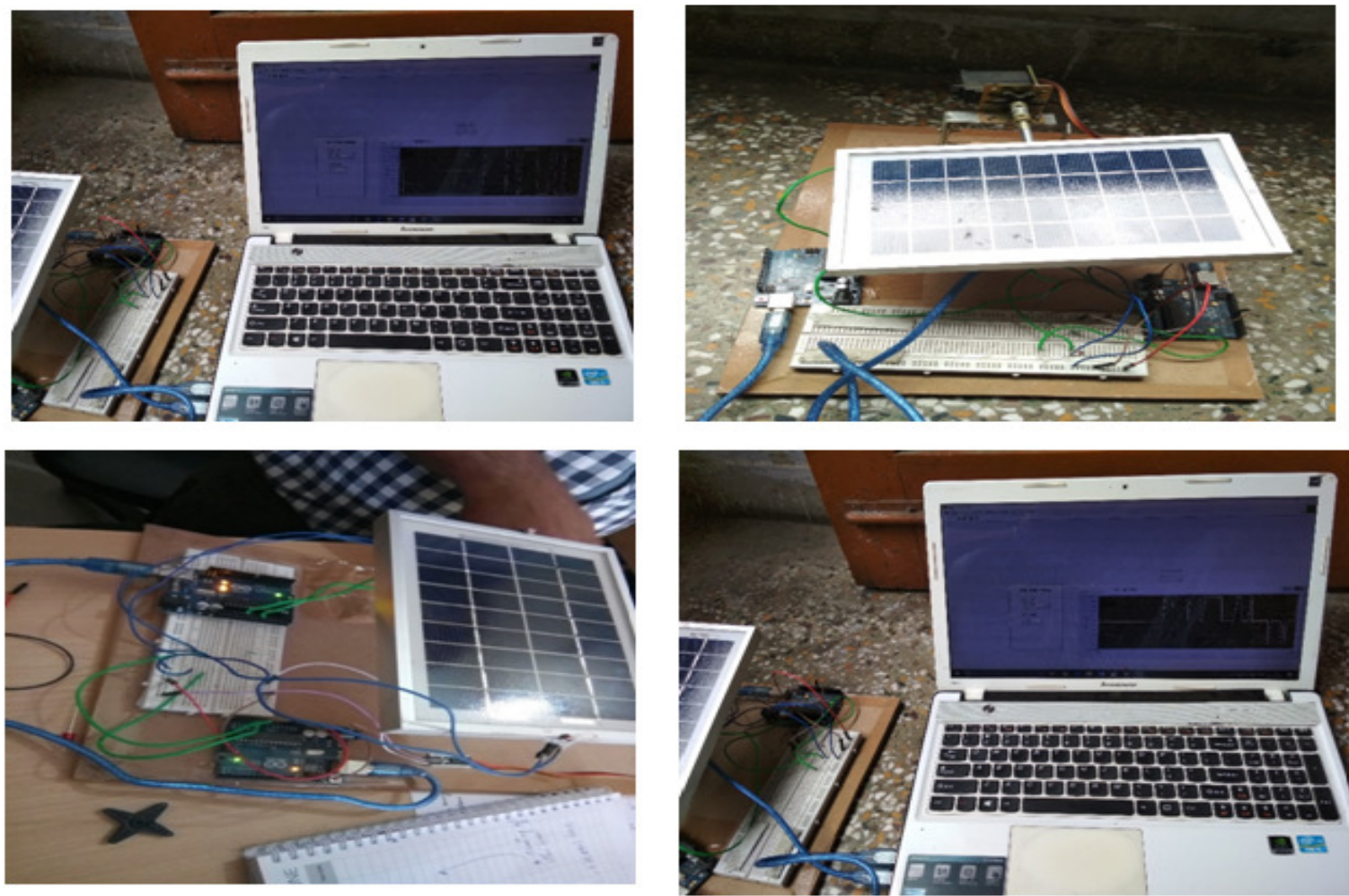

\subsection{Circuit Diagram}

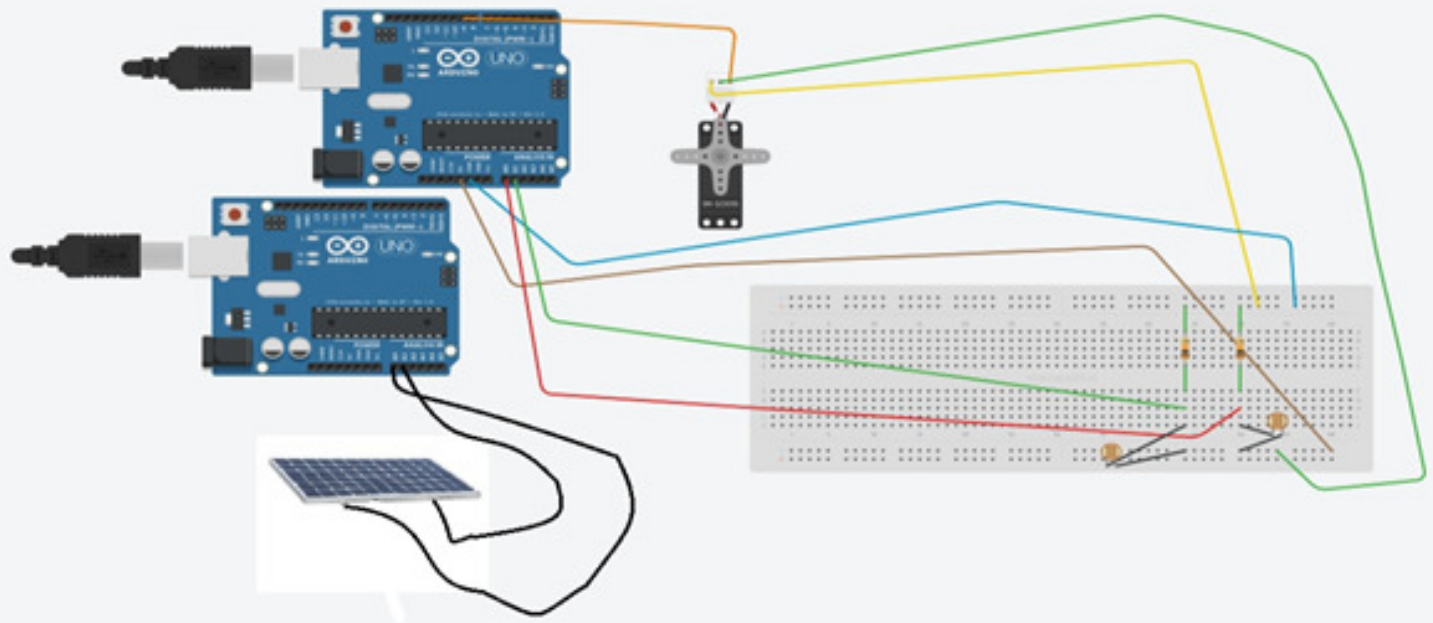

Figure 7. Circuit diagram of the prototype model 
International Journal of Instrumentation and Control Systems (IJICS) Vol.7, No.3, July 2017

\section{RESULTS AND DISCUSSIONS}

The data's from the LabVIEW software is exported directly to excel sheets. With the acquired data's of the solar panel continuously, different voltage graphs are formulated of different day's. The characteristics of the simulated PV panel is shown in Table 1. The output power of the solar array is mainly influenced by ambient temperature and irradiation. However, typically, the variations in temperature are slower than the possible changes in irradiation. For this reason, temperature has less impact on the dynamic response of the system. Fast moving, sporadic, clouds can lead to sudden changes in the output power of the solar array. Therefore, it has to be tested under different irradiation levels to verify the dynamic performance of the tracking the maximum power point tracking. The simulation results are shown in the following Figures.

DAY 1: $05^{\text {th }}$ March, 2017

TIME: 10:00 AM - 12:22 PM

PLACE: JALANDHAR

DURATION: 2.30 HOURS

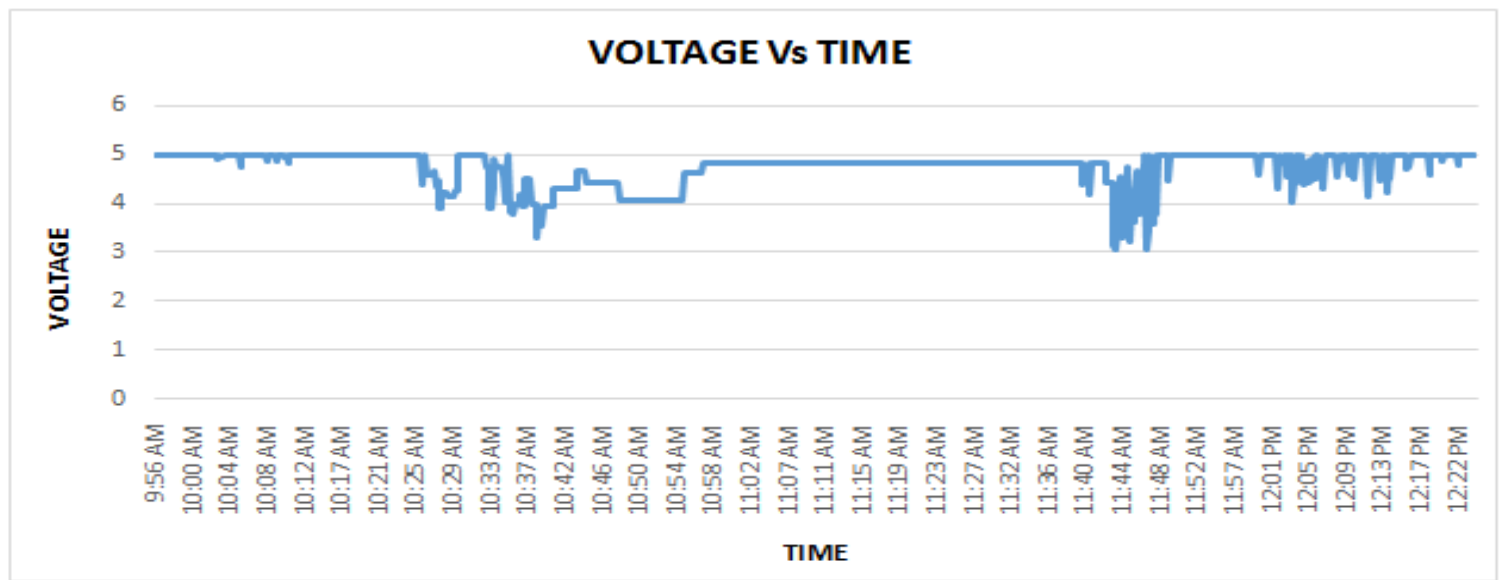

Figure 6

DAY 1: $07^{\text {th }}$ March, 2017

PLACE: JALANDHAR

TIME: 1:12 PM - 4:01 PM

DURATION: 3:00 HOURS

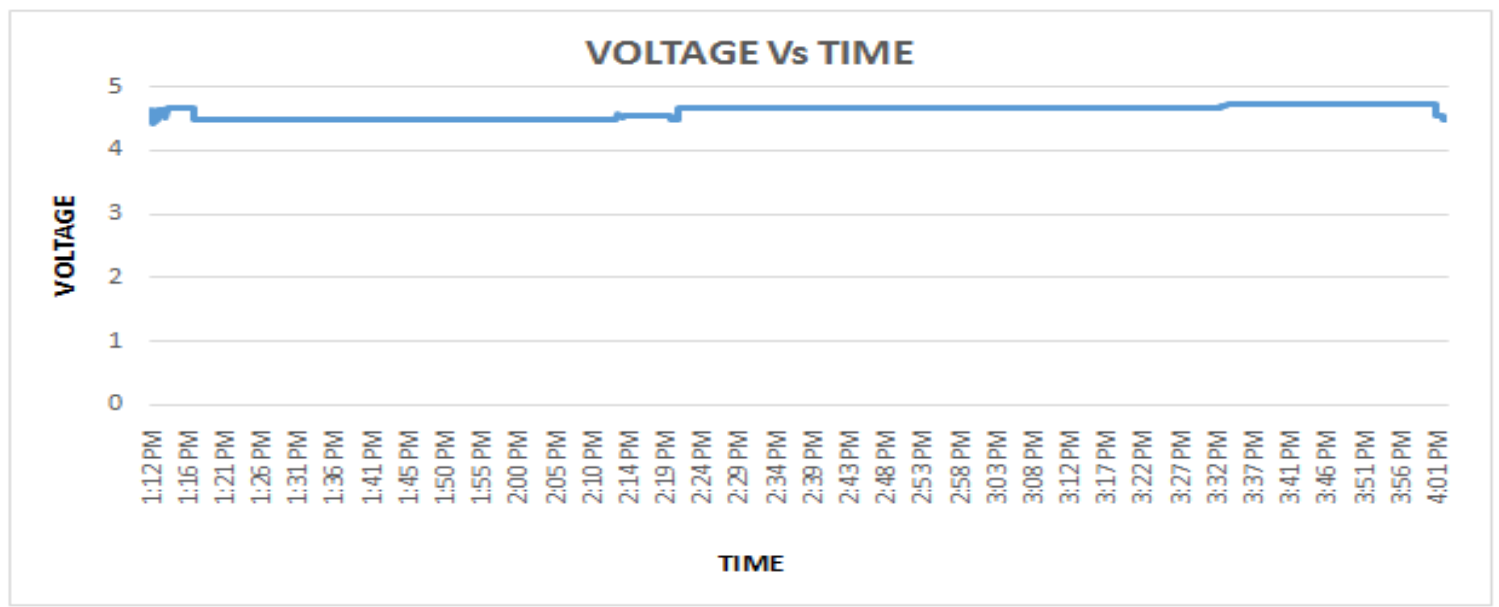

Figure 7 
International Journal of Instrumentation and Control Systems (IJICS) Vol.7, No.3, July 2017

\section{DAY 1: $12^{\text {th }}$ March, 2017 PLACE: JALANDHAR}

TIME: 5:40 AM - 8:28 AM

DURATION: 3:00 HOURS

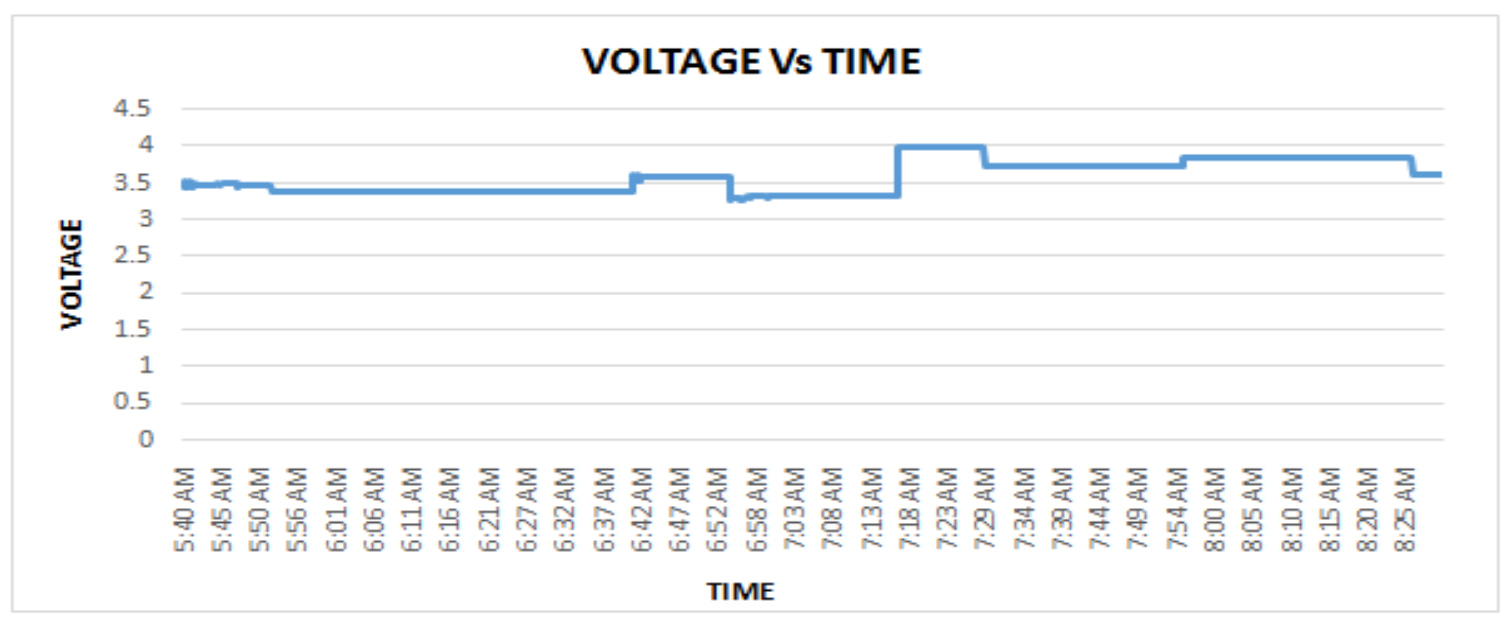

Figure 8

Table 2: Comparison of Experimental Results

\begin{tabular}{|c|c|c|c|c|c|}
\hline Exp.No & Time & Duration & $\begin{array}{l}\text { Maximum } \\
\text { Voltage }\end{array}$ & $\begin{array}{l}\text { Minimum } \\
\text { Voltage }\end{array}$ & Constant Voltage \\
\hline Unit & & Hours & Volts & Volts & Volts \\
\hline 1 & 10:00am-12:22pm & 2.30 & 5 & 3 & 4.9 \\
\hline 2 & $1: 12 \mathrm{pm}-4: 01 \mathrm{pm}$ & 3.00 & 4.7 & 4.4 & 4.7 \\
\hline 3 & $5: 40 \mathrm{am}-8: 28 \mathrm{am}$ & 3.00 & 4 & 3.3 & 3.7 \\
\hline
\end{tabular}

The graph was plotted between voltage and time in figure (6-8). Figure 6 shows the voltages from $10.00 \mathrm{am}$ to $12.22 \mathrm{pm}$. Between the time duration of $10.28 \mathrm{am}$ to $11.30 \mathrm{am}$ and from $11.40 \mathrm{am}$ to 12.44 pmvoltages were partially fluctuating due to some external environment factors like cloudy weather, low sun intensity. But during the time duration from $11.00 \mathrm{pm}$ to $12.00 \mathrm{pm}$ the voltage is maximum due to maximum sun intensity.

Figure 7 shows the voltages from $1.12 \mathrm{pm}$ to $4.01 \mathrm{pm}$ and it has been observed that the maximum voltage is 4.7 volts and the minimum voltage is 4.4 volts. The fluctuation of voltages was less and got a constant voltage of 4.7 volts. On this day the intensity of sunlight was more what equal so the fluctuation was less.

Figure 8 shows the voltage from 5:40am to 8:28am and here the voltage was in the range of 3.5 volts to 4 volts. The maximum voltage output was 4 volts and the fluctuation was less. The constant was 3.7 volts.

The output power of the solar array is mainly influenced by ambient temperature and irradiation. However, typically, the variations in temperature are slower than the possible changes in irradiation. For this reason, temperature has less impact on the dynamic response of the system. Fast moving, sporadic, clouds can lead to sudden changes in the output power of the solar array. 
International Journal of Instrumentation and Control Systems (IJICS) Vol.7, No.3, July 2017

\section{CONCLUSION}

This paper presents the simulation of real time data acquisition of solar panel. From the above study, the solar panel's real time voltages are imported from LabVIEW to excel sheet. .This voltage is varying with respect to the atmospheric condition such as irradiation value of solar light and atmospheric temperature. The above results shows the voltage variation and behaviour of the solar panel recorded during different duration of time and days. Due to the low and high intensity of the sunrays, the voltage of the solar panel varies. This is easily depicted from the above results. The total simulation has been successfully simulated in LabVIEW using Arduino. The servomotor needs to be calibrated every time whenever it gets started from its position.

\section{REFERENCES}

[1] A. A. Nafeh, F. H. Fahmy, O. A. Mahgoub, and E. M. El-Zahab, "Developed algorithm of maximum power tracking for stand-alone photovoltaic system," Energy Sources, vol. 20, pp. 45-53, Jan. 1998.

[2] P. Huynh and B. H. Cho, "Design and analysis of a microprocessor controlled peak-power-tracking system,” IEEE Trans. Aerosp. Electron. Syst., vol. 32, pp. 182-189, Jan. 1996.

[3] M. G. Jaboori, M. M. Saied, and A. A. Hanafy, "A contribution to the simulation and design optimization of photovoltaic systems,” IEEE Trans. Energy Conv., vol. 6, pp. 401-406, Sept. 1991.

[4] E. Koutroulis, K. Kalaitzakis, and N. C. Voulgaris, "Development of a microcontroller-based, photovoltaic maximum power point tracking control system," IEEE Trans. Power Electron., vol. 16, no. 21, pp. 46-54, Jan. 2001.

[5] K. Irisawa, T. Saito, I. Takano, and Y. Sawada, "Maximum power point tracking control of photovoltaic generation system under non-uniform insolation by means of monitoring cells," in Conf. Record Twenty-Eighth IEEE Photovoltaic Spec. Conf., 2000, pp. 1707-1710.

[6] T.-Y. Kim, H.-G. Ahn, S. K. Park, and Y.-K. Lee, "A novel maximum power point tracking control for photovoltaic power system under rapidly changing solar radiation," IEEEInt.Symp.Ind.Electron. ,2001, pp. 1011-1014.

[7] V. Arcidiacono, S. Corsi, and L. Lambri, "Maximum power point tracker for photovoltaic power plants," in Proc. IEEE Photovoltaic Spec. Conf., 1982, pp. 507-512.

[8] T. Hiyama, S. Kouzuma, and T. Imakubo, "Identification of optimal operating point of PV modules using neural network for real time maximum power tracking control," IEEE Trans. Energy Convers., vol. 10, no. 2, pp. 360-367, Jun. 1995.

[9] Information Technology Act 2000, India, available at: https://www.elprocus.com/microcontrollerstypes-and-applications/ (visited on October 28, 2016)

[10] Information Technology Act 2000, India, available at: http://digital.csic.es/bitstream/10261/127788/7/D-c-\%20Arduino\%20uno.pdf (visited on December 12, 2016)

[11] Information Technology Act 2000, India, available at: https://en.wikipedia.org/wiki/LabVIEW (Last modified on June 22, 2017) 
International Journal of Instrumentation and Control Systems (IJICS) Vol.7, No.3, July 2017

[12] Information Technology Act 2000, India, available at:

file:///C:/Program\%20Files\%20(x86)/Arduino/reference/www.arduino.cc/en/Guide/Windows.html (visited on January 6, 2017)

[13] Johnson Mathew, G. Vincent, "Realtime parameter monitoring and maximum power point estimation of solar photovoltaic array, "Next Generation Intelligent Systems (ICNGIS) International Conference on 1-3 sept,2016.

[14] M. Fuentes, M. Vivar, J. M. Burgos, J. Aguilera, J. A. Vacas, "Design of an accurate, low cost autonomous data logger for PV system monitoring using Arduino that complies with IEC standards" Solar Energy materials and solar cells, Volume.130, pp 529 - 543.

[15] Farid Touati, M. A. Al-Hitmi, Noor Alam Chowdhury, Jehan Abu Hamad, Antonio J. R San Pedro Gonzales, "Investigation of solar PV performance under Doha weather using a customized measurement and monitoring system” Renewable Energy, Volume 89, pp 564-577, 2016.

[16] Çagatay Ersin, R.Gurbuz, A.K. Yakut, "Application of an automatic plant Irrigation system based arduino microcontroller using solar energy", Solid State Phenomena, Volume.251, pp. 237-241, 2016.

[17] N.N.Mahzan, A.M. Omar, L.Rimon, S.Z. Mohammad Noor, M.Z. Rosselan, "Design and development of an arduino based data logger for Photovoltaic monitoring system" International Journal of. Simulation. Systems, Science \& Technology, Volume 17, No-41, pp. 1-15, 2015.

[18] Saraswati Teli, Mani.C, "Smart real time embedded Arduino based data acquisition system" International Journal Of Research in Engineering and Technology, Volume 04, pp.258-262, 2015.

\section{AUTHORS BIOGRAPHY}

Shubhankar Mandal received the Bachelor degree in Instrumentation \&Control Engineering from Haldia Institute of Technology, Haldia, West Bengal, India in 2015. He will be completing the M.Tech degree in Instrumentation \& Control Engineering from National Institute of Technology, Jalandhar, Punjab, India in August 2017.

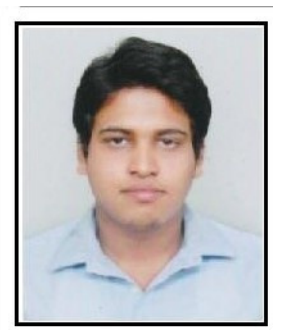

